Agricultural Meteorology, 15(1975) 393-404

(C) Elsevier Scientific Publishing Company, Amsterdam - Printed in The Netherlands

\title{
A BEHAVIOUR MODEL TO SIMULATE STOMATAL RESISTANCE
}

\author{
T. TAKAKURA*, J. GOUDRIAAN and W. LOUWERSE .. \\ Department of Theoretical Production Ecology, Agricultural University, Wageningen (The \\ Netherlands)
}

(Received July 31, 1975; accepted September 3, 1975)

\section{ABSTRACT}

Takakura, T., Goudriaan, J. and Louwerse, W., 1975. A behaviour model to simulate stomatal resistance. Agric. Meteorol., 15: 393-404.

The purpose of the present study is to make a behaviour model which might have a different structure from the real system but acts in the same way as the real system does in the region considered. In the present model, the basic working hypotheses are a functional relationship between stomatal resistance and internal $\mathrm{CO}_{2}$ concentration and an effect of leaf temperature on internal resistance.

It is found that stomatal resistance in the model responds to changes in light, external $\mathrm{CO}_{2}$ concentration and leaf temperature in a way which is experimentally confirmed.

At the present stage of work on plant growth simulation, the model may be good enough to account for the rather complicated interactions that govern stomatal movement, although some clear phenomena can not be explained.

\section{INTRODUCTION}

Stomatal behaviour as affected by various environmental conditions has been widely investigated experimentally and is well reviewed by Meidner and Mansfield (1968). According to these investigations, changes of light would be the most obvious environmental factor that affects stomatal movement. Therefore the first and most common approach to simulate stomatal behaviour in sophisticated models of plant growth was to express it as a function of light intensity (De Wit et al., 1970; Goudriaan, 1973). Recently, a very sophisticated model for computer simulation has been developed (Penning de Vries, 1972). It accounts for the interaction between relative water content, light intensity and $\mathrm{CO}_{2}$ concentration through the hypothesis that the pressure potential of the guard cells which causes the aperture change in stomata consists of the sum of these three components. The complexity of the model prevents its use in crop growth models.

*Present address: Department of Horticultural Engineering, Chiba University, Matsudo, Japan 271. 
The purpose of the present study is to create a simple behaviour model which might have a different structure from the real system but acts in the same way as the real system does in the region considered. Therefore, this model does not account for the complicated movement caused by different day-lengths (Mansfield and Heath, 1963), opening in the dark, and the change of chemical composition in epidermal and guard cells which is reported to be well correlated with the stomatal movement (Pearson, 1973; Hsiao et al., 1973).

Apart from the effect of water stress on stomatal aperture, investigations on the interaction of external $\mathrm{CO}_{2}$ concentration and light intensity were carefully carried out by Heath and Russell (1954). Although a detailed analysis leaves open several possible explanations, it is apparent that the direct effect of photosynthesis is to reduce the $\mathrm{CO}_{2}$ concentration in the intercellular space. This generates a signal which is transmitted to govern the stomatal aperture. Furthermore, changes in external $\mathrm{CO}_{2}$ concentration affect stomatal aperture (Pallas, 1965; Jones and Mansfield, 1970). Therefore, it is possible to build a model in which stomatal movement is brought about solely by the change of internal $\mathrm{CO}_{2}$ concentration which results from whole-leaf photosynthesis and respiration. For this purpose, a simple functional relationship between stomatal resistance and internal $\mathrm{CO}_{2}$ concentration has been established based on experimental data by W. Louwerse (unpublished data, 1973).

The study of the direct effect of light, evident through the effects of the light spectrum and the diurnal rhythm of stomatal movement, is beyond the scope of the present model. However, the effect of water stress can be super-imposed in the model as it is in the plant growth model (Goudriaan, 1973). In the present model, stomatal resistance responds to changes in light, external $\mathrm{CO}_{2}$ concentration and leaf temperature in a way which is experimentally confirmed; the basic working hypotheses being the functional relationship between stomatal resistance and internal $\mathrm{CO}_{2}$ concentration and the effect of leaf temperature on internal resistance.

The model has been programmed in CSMPIII and for better understanding of the computer program itself as well as for better lucidity, the equations in the present paper are written in CSMP.

\section{BASIC STRUCTURE OF THE MODEL}

The formulae for photosynthesis and stomatal resistance in accordance with the scheme in Fig.1, cannot be given in an explicit form, but are defined within a set of simultaneous nonlinear equations in which symbols and conversion factors occur as defined in the Notation.

\section{Photosynthesis}

The limiting factor for photosynthesis is either light intensity (PHOTO $=$ 


\section{NOTATION}

List of variables*

\begin{tabular}{|c|c|c|}
\hline Name & Meaning & Dimensiọn \\
\hline ABSRAD & total absorbed radiation per leaf area & $\mathrm{J} \mathrm{m}^{-2} \mathrm{~s}^{-1}$ \\
\hline EHL & latent heat loss by transpiration per leaf area & $\mathrm{J} \mathrm{m}^{-2} \mathrm{~s}^{-1}$ \\
\hline SHL & sensible heat loss per leaf area & $\mathrm{J} \mathrm{m}^{-2} \mathrm{~s}^{-1}$ \\
\hline TA & air temperature & $\mathrm{C}$ \\
\hline TCP & leaf temperature & $\mathrm{C}$ \\
\hline RHOCP & volumetric heat capacity of the air & $\mathrm{J} \mathrm{m}^{-3} \mathrm{C}^{-1}$ \\
\hline PSCH & psychrometer constant & $\mathrm{mb} \mathrm{C}^{-1}$ \\
\hline SLOPE & $\begin{array}{l}\text { slope of the saturated vapour pressure curve } \\
\text { at air temperature }\end{array}$ & $\mathrm{mb} \mathrm{C}^{-1}$ \\
\hline SVCA & saturated vapour pressure at air temperature & $\mathrm{mb}$ \\
\hline $\mathrm{VCA}$ & actual vapour pressure of the air & $\mathrm{mb}$ \\
\hline RA & $\begin{array}{l}\text { resistance of the boundary layer for water } \\
\text { and heat }\end{array}$ & $\mathrm{s} \mathrm{m}^{-1}$ \\
\hline SR & stomatal resistance for water & $\mathrm{s} \mathrm{m}^{-1}$ \\
\hline LIGHT & absorbed photosynthetic active light & $\mathrm{J} \mathrm{m}^{-2} \mathrm{~s}^{-1}$ \\
\hline $\mathrm{EFF}$ & $\begin{array}{l}\text { slope of the photosynthesis light curve at } \\
\text { LIGHT }=0\end{array}$ & $\mathrm{~kg} \mathrm{CO}_{2} \mathrm{~m}^{2} \mathrm{~s} \mathrm{~J}^{-1} \mathrm{ha}^{-1} \mathrm{hr}^{-1}$ \\
\hline PHOTO & rate of photosynthesis per leaf area & $\mathrm{kg} \mathrm{CO}_{2} \mathrm{ha}^{-1} \mathrm{hr}^{-1}$ \\
\hline RESP & rate of respiration per leaf area & $\mathrm{kg} \mathrm{CO}_{2} \mathrm{ha}^{-1} \mathrm{hr}^{-1}$ \\
\hline CO2ST & $\begin{array}{l}\text { carbon dioxide concentration in the stomatal } \\
\text { cavity }\end{array}$ & vpm \\
\hline VPMO & outside carbon dioxide concentration & vpm \\
\hline
\end{tabular}

*We have adopted 68.4 as the conversion factor from vpm m s$~^{-1}$ to $\mathrm{kg} \mathrm{CO}_{2} \mathrm{ha}^{-1} \mathrm{hr}^{-1}$, and 1.6 as the ratio between the diffusivity of water vapour and $\mathrm{CO}_{2}$ in air.

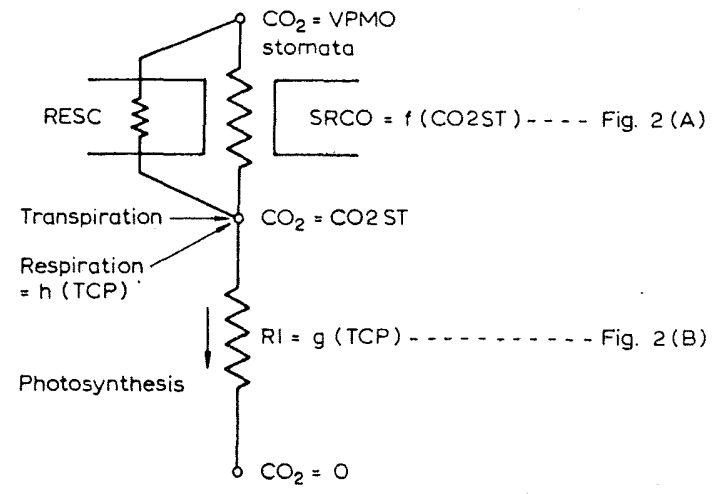

Fig.1. Basic structure of the model.

EFF $\times$ LIGHT) or carbon dioxide diffusion $(\mathrm{PHOTO}=\mathrm{CO} 2 \mathrm{ST} / \mathrm{RI} \times 68.4)$.

These two expressions are combined in the statement:

PHOTO = AMIN1 (EFF $\times$ LIGHT, CO2ST/RI 68.4$)$ 
396

RI must be visualized as the resistance between the stomatal cavity and the photosynthetically active site, whereby the $\mathrm{CO}_{2}$ concentration in the latter is supposed to be zero. Eq.1 is not an explicit formulation because CO2ST depends on PHOTO according to

CO2ST $=$ VPMO $-($ PHOTO-RESP $) \times 1.6 \times(\mathrm{SR}+\mathrm{RA}) / 68.4$

The stomatal resistance $\mathrm{SR}$ is considered to change from its minimum value to its maximum value according to the aperture of the stomata. If this mechanism is simplified, this relationship can be schematized in Fig.2A and also expressed in Fig. 3 with the experimental data obtained by W. Louwerse (unpublished data, 1973). Now, SR is a function of CO2ST:

$\mathrm{SR}=\mathrm{AFGEN}(\mathrm{SRTB}, \mathrm{CO} 2 \mathrm{ST})$

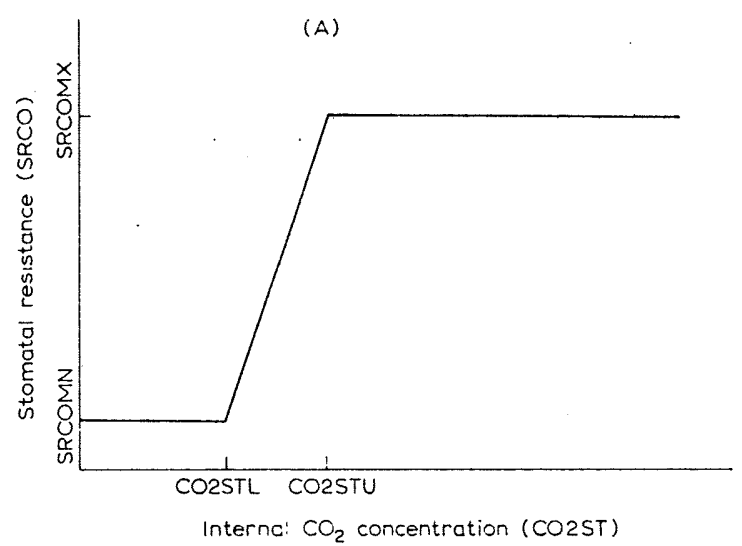

(3)

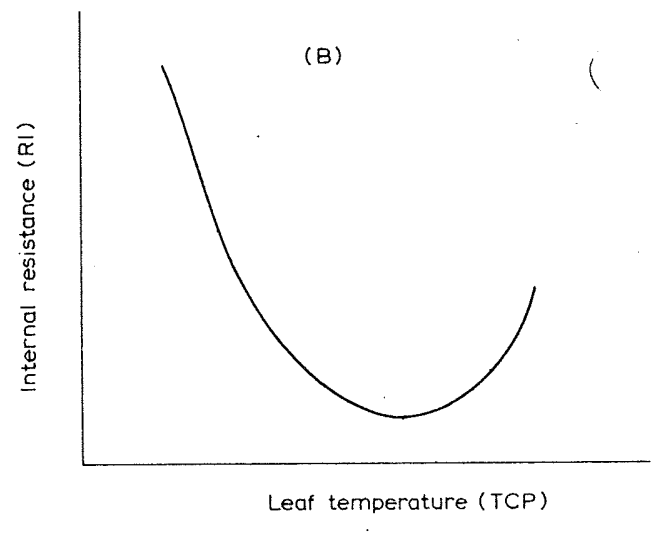

Fig.2. Diagrammatic representation of stomatal response to internal $\mathrm{CO}_{2}$ concentration (A), and the effect of temperature on internal resistance (B).

There is no need to make a parallel circuiting with the cuticular resistance, as this is already represented in the data for SR. In the case of a fixed RI and RESP these three simultaneous equations give a basic definition.

\section{Leaf temperature}

Usually, RESP and RI are functions of the leaf temperature. It is assumed that RESP increases exponentially with leaf temperature and has a $Q_{10}$ of 2 ;

$\operatorname{RESP}=5 . \times 2 \times \times\{[\operatorname{LIMIT}(0 ., 40 ., \mathrm{TCP})-20] \times 0.1\}$

A more sophisticated treatment may be based on the work of Penning de

Vries (1972). The relationship of RI with temperature is presented in Fig.2B. It is written as:

$\mathrm{RI}=\mathrm{AFGEN}(\mathrm{TRITB}, \mathrm{TCP})$ 




Fig. 3. Simplified relationships between stomatal resistance (SR) and internal $\mathrm{CO}_{2}$ concentration for beans and maize. Crosses are measured data for maize, and dots for beans under various light conditions (after W. Louwerse, unpublished data, 1973).

The leaf temperature can be calculated from the energy balance, thereby yielding the rate of transpiration as well.

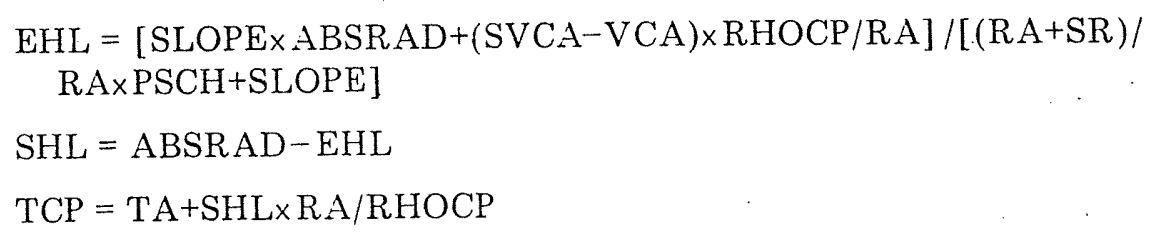

These 8 simultaneous equations give a complete definition.

\section{Solution technique}

The simulation language CSMP contains a special feature called IMPLICIT LOOP, which enables the solution of a set of simultaneous equations. In fact 
it is nothing more than the invocation of a numerical iteration method. In principle the use of the implicit loop is very simple. One of the variables must be chosen to lead the iteration procedure. In this case CO2ST is chosen as the controlling variable.

The implicit loop can be written as:

$$
\begin{aligned}
& \text { CO2ST = IMPL }(300,0.01, \mathrm{CEND}) \\
& \mathrm{SR}=\mathrm{AFGEN}(\mathrm{SRTB}, \mathrm{CO} 2 \mathrm{ST}) \\
& \mathrm{EHL}=[\mathrm{SLOPE} \times \mathrm{ABSRAD}+(\mathrm{SVCA}-\mathrm{VCA}) \times \mathrm{RHOCP} / \mathrm{RA}] /[(\mathrm{RA}+\mathrm{SR}) / \\
& \quad(\mathrm{RA} \times \mathrm{PSCH})+\mathrm{SLOPE}] \\
& \mathrm{SHL}=\mathrm{ABSRAD}-\mathrm{EHL} \\
& \mathrm{TCP}=\mathrm{TA}+\mathrm{SHL} \times \mathrm{RA} / \mathrm{RHOCP} \\
& \mathrm{RESP}=5 . \times 2 \times \times\{[\mathrm{LIMIT}(0 ., 40 ., \mathrm{TCP})-20 .] \times 0.1\} \\
& \mathrm{RI}=\mathrm{AFGEN}(\mathrm{TRITB}, \mathrm{TCP}) \\
& \mathrm{PHOTO}=\mathrm{AMINI}(\mathrm{EFF} \times \mathrm{LIGHT}, \mathrm{CO} 2 \mathrm{ST} / \mathrm{RI} \times 68.4) \\
& \mathrm{CEND}=\mathrm{VPMO}-(\mathrm{PHOTO}-\mathrm{RESP}) \times 1.6 \times(\mathrm{SR}+\mathrm{RA}) / 68.4
\end{aligned}
$$

The last statement calculates the value of CO2ST, which is used in the second iteration. To indicate the end of the loop the name of the variable must be the same as the last argument in the opening statement of the loop. The two other arguments denote respectively the first guess of CO2ST (which has no influence on the final result), and the error bound of the result. Variables which are driving forces and do not change during the iteration, should . be given as parameters or calculated elsewhere in the program. For instance, RA can be calculated from the windspeed and the width of the leaves, and TA can be given as a parameter.

\section{Practical difficulties}

The implicit loop presented above is not fool-proof. The shape of the SRTB function (Fig.2A) with its very steep section, and two horizontal sections causes a divergence in the numerical procedure. Because of this inadequacy, another program has been constructed, not different in function, but much more complicated in appearance. First an attempt is made to obtain a solution in the upper horizontal section. That means that in the case of closed stomata, CO2ST should be larger than CO2STU. If so, the solution is found. If not, the lower horizontal section is tried. With open stomata CO2ST should be less than CO2STL. If so, a solution is found. If not, the solution must lie between CO2STL and CO2STU. In that case a straight line can be used representing the steep section in the SRTB function. The first two procedures are defined in the macro called STOMAT, the latter procedure in the macro called CO2FND. 


\section{MODEL BEHAVIOUR}

In order to compare the model behaviour with the experimental results reported previously, the model with suitable parameters for maize has been run and the results are summarized in Figs.4, 5, 6 and 7. Because the parameters used are derived from different species, the comparison of the magnitudes of stomatal response to certain environmental conditions between the model and the experimental data can not be validated as yet. However, it appears reasonable that the model summarizes the rather complicated logic of interaction behind these experimental data.

In Fig. $4 \mathrm{~A}$ the simulated photosynthesis response curves and the changes of
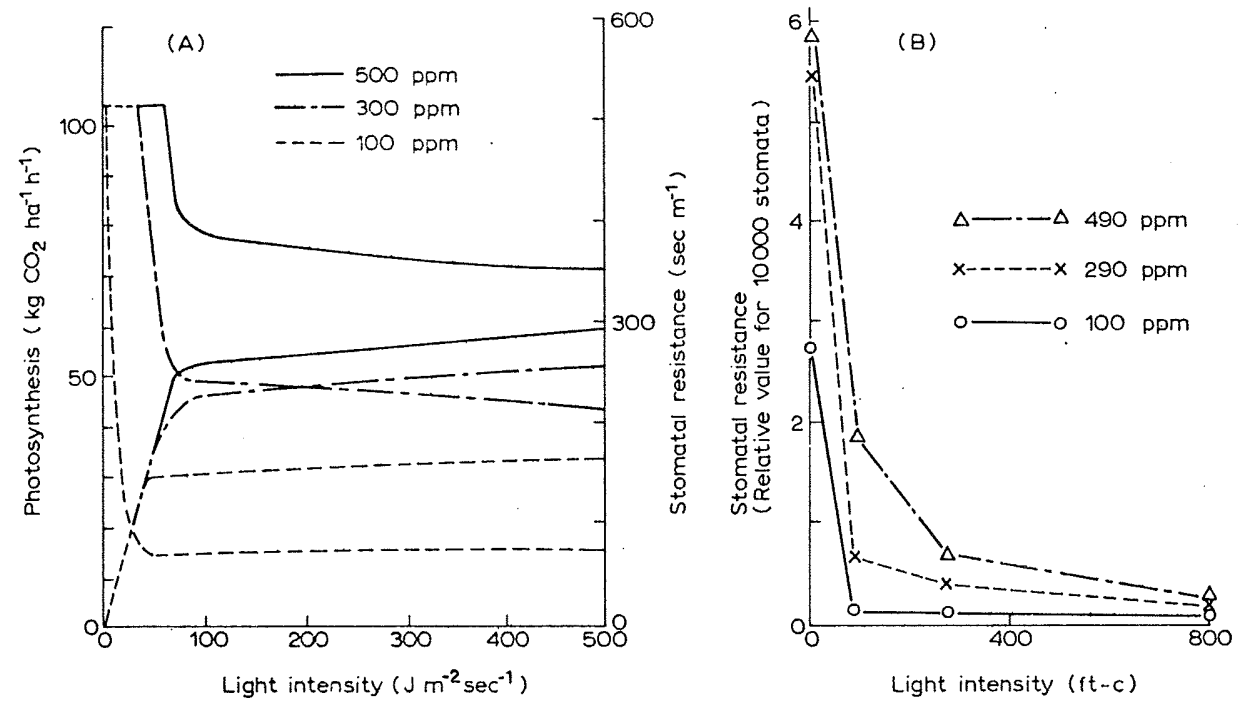

Fig.4. Stomatal resistance as affected by light intensity and $\mathrm{CO}_{2}$ concentration: A. model behaviour with photosynthesis response curves; B. experimental results after Heath and Russell (1954).

stomatal resistance are shown for different light intensities in a wide range of $\mathrm{CO}_{2}$ concentrations. Experimental results by Heath and Russell (1954) are given in Fig. 4B. The important point to notice is that the stomatal resistance of the model is determined by both light and $\mathrm{CO}_{2}$ concentration which is in good agreement with the experiments. It is also seen that a sharp decrease of stomatal resistance occurs at low light intensity and exposure to higher light intensities has no appreciable effect on the subsequent response to light intensity. In the model, fixed maximum stomatal resistance is reached in all cases at lower intensities because of the assumption of the same maximum . resistance through the whole range of $\mathrm{CO}_{2}$ concentration.

The main difference between the model behaviour and the experimental result is that at high light intensity stomatal resistance of the model is rather high under high external $\mathrm{CO}_{2}$ concentration. A good comparison is, however, 
impossible because of the different scale units and the differences in species.

The equilibrium of stomatal resistance at low light intensities results from the fact that the transition from maximum stomatal resistance to minimum resistance occurs around 100 p.p.m. internal $\mathrm{CO}_{2}$ concentration where the drastic change of stomatal resistance occurs depending on the species. A transition at 220 p.p.m. shows a much less steep change in stomatal resistance as may be seen in Fig.7. It is therefore suggested that this behaviour model will, with proper parameters, mimic these observations reasonably.

The changes of photosynthesis and internal $\mathrm{CO}_{2}$ concentration due to external $\mathrm{CO}_{2}$ concentration are shown in Fig.5. The results in Fig. 5 reflect also a departure from the experimental results, the transition not being observed. The transition is obtained by using the relationship shown in Fig.2A.
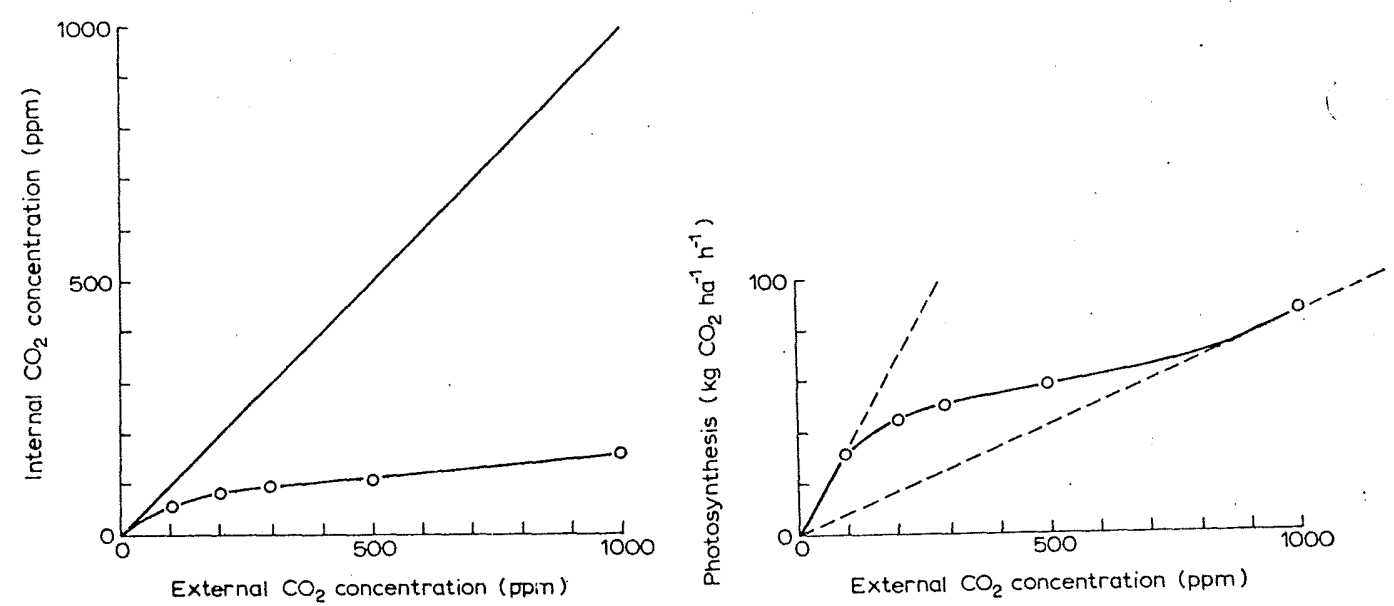

Fig. 5. Model behaviour of photosynthesis and internal $\mathrm{CO}_{2}$ concentration in relation to external $\mathrm{CO}_{2}$ concentration (temperature is $20^{\circ} \mathrm{C}$, light intensity is $500 \mathrm{~J} \mathrm{~m}^{-2} \mathrm{~s}^{-1}$ ). The two dotted straight lines in the right figure are determined by the minimum and maximum stomatal resistances which are shown by two horizontal lines in Fig. $2 \mathrm{~A}$. The straight line in the left figure represents the one-to-one relationship between internal and external concentrations.

Although this simple and clear functional relationship in this figure is a good approximation of the several measurement series, it is possible that stomata do not act as ideal thermostats and show a rather gradual increase of stomatal resistance after the drastic change. This suggests that the photosynthesis curve is less straight at high $\mathrm{CO}_{2}$ concentration and is formed as if $\mathrm{CO}_{2}$ is saturated. However, it is clear that this shape of the curve results from stomatal closure and not from $\mathrm{CO}_{2}$ saturation. It is obvious that more experimental investigation is needed to clarify this phenomenon.

From Fig. 5 it is clear that under the conditions of normal temperature and high light intensity internal resistance of maize is kept considerably low because of the high maximum resistance of the stomata compared to the internal resistance. 
The model response to temperature and the experimental result of Stålfelt (1962) are shown in Fig.6B. In the present model, it is assumed that
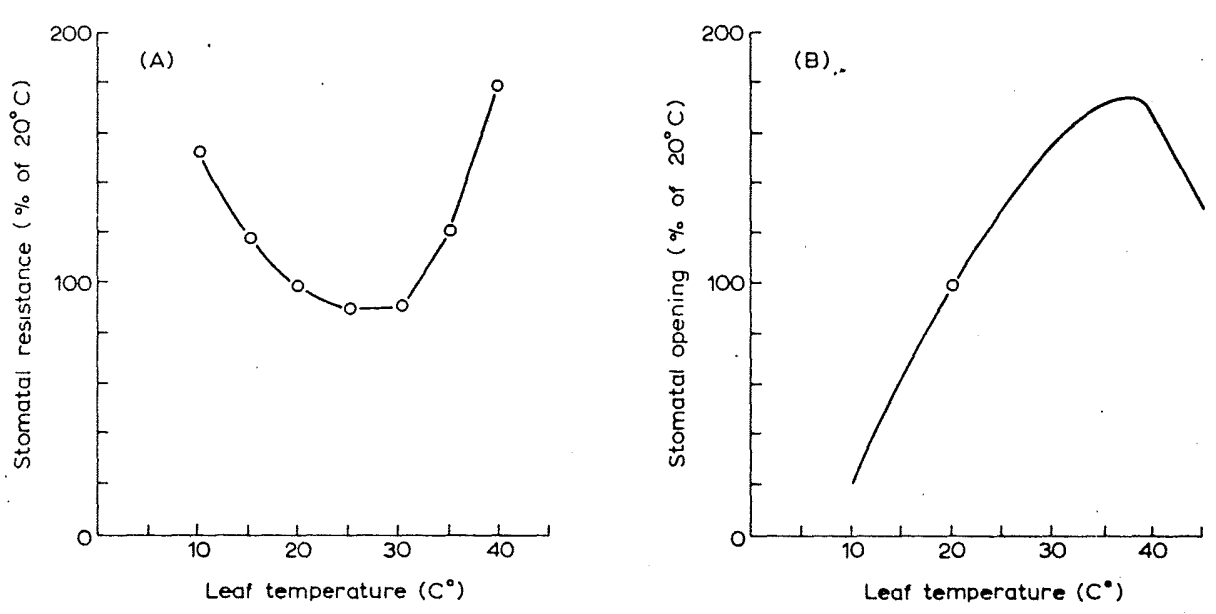

Fig.6. Effect of temperature on stomatal resistance: A. model behaviour in saturated light condition and $\mathrm{CO}_{2}$ concentration is 300 p.p.m.; B is the stomatal opening in Vicia faba in light of 20,000 lux after Stålfelt (1962).

there is no direct effect of temperature on stomatal resistance, but that temperature has its effect through changes in photosynthesis and respiration. Photosynthesis changes with leaf temperature through internal resistance under light saturated conditions and the change of respiration with temperature contributes to the level of internal $\mathrm{CO}_{2}$ concentration. The shape of the curve in Fig.6A is mainly determined by the relationship between the internal resistance and leaf temperature. The curve steepens at higher temperatures because of $\mathrm{CO}_{2}$ generation by respiration. There is good agreement between the model behaviour and the experimental result if the difference of species is considered. However, stomatal response to the change of temperature in the dark can not be explained by this model.

In order to examine the range of $\mathrm{CO}_{2}$ concentration in which a drastic transition in stomatal resistance occurs in the model, this range (Fig.2A) has been narrowed from 40 p.p.m. (80-120 p.p.m. of internal $\mathrm{CO}_{2}$ concentration) to 2 p.p.m. (99-101 p.p.m.). A more rapid change of stomatal resistance in this narrower range reduces stomatal resistance in the lower concentration of the previous transition range, and an increase in the higher concentration gives wider constant regions at both sides. This change does not give us the different pattern of the frequency of the occurrence where the internal $\mathrm{CO}_{2}$ concentration falls. The result is given in Table I. It is considered that this change might save computing time because of the wider 
Frequency of the occurrence of the internal equilibrium $\mathrm{CO}_{2}$ concentration in the three regions of Fig. $2 \mathrm{~A}$ (Temperature is $20^{\circ} \mathrm{C}, \mathrm{CO}_{2}$ is 300 p.p.m. and light is changed from 0 to $500 \mathrm{~J} \mathrm{~m}^{-2} \mathrm{~s}^{-\mathrm{P}}$ )

\begin{tabular}{lccc}
\hline Transition range: & $80-120$ p.p.m.* & $99-101$ p.p.m.* & 219-220 p.p.m.** \\
\hline Lower constant region & $0 \%$ & $0 \%$ & $0 \%$ \\
Transition & 92 & 92 & 96 \\
Upper constant region & 8 & 8 & 4 \\
\hline
\end{tabular}

*Maize; **beans.

constant region of stomatal resistance. However, in our computer runs there is no solution which drops in this increased constant region and more computing time due to the change of the slope has been required.

In Fig. 7A it is shown that stomatal resistance changes due to the shift of the transition range to higher internal $\mathrm{CO}_{2}$ concentration when other parameters are kept the same as for maize. The change of stomatal response due to the change of light intensity is given as well. It is apparent that a shift of the transition range to higher $\mathrm{CO}_{2}$ concentration results in lower stomatal resistances in higher $\mathrm{CO}_{2}$ ranges.

Gaastra (1959) reported the stomatal response of turnips to light intensity as given in Fig. 7B. The rapid change of stomatal resistance under lower light intensity and the shift of the occurrence of its drastic change to higher $\mathrm{CO}_{2}$ range due to high light intensity are in good agreement with the simulated results.

However, the rather constant stomatal resistance in higher $\mathrm{CO}_{2}$ concentration under high light intensity which was obtained experimentally could not be reproduced by the present model, but this could be due to differences in species.

\section{CONCLUSION}

We can not deny that there are some clear phenomena which can not be explained by the present model. However, for the present stage of the simulation work of plant growth, the model may be good enough to account for the rather complicated interrelations that govern the stomatal movement. Furthermore, it could trigger experimental work to determine direct and indirect effects of environmental factors on stomatal behaviour.

\section{ACKNOWLEDGEMENTS}

The authors gratefully acknowledge Prof. C. T. de Wit and Dr. F. W. T. Penning de Vries for their helpful advice and discussion. The first author is 


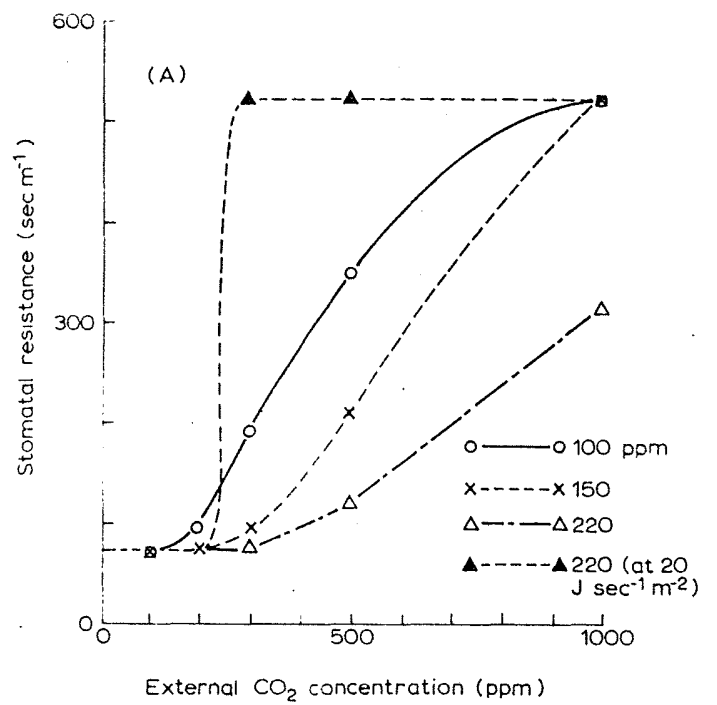

(8)

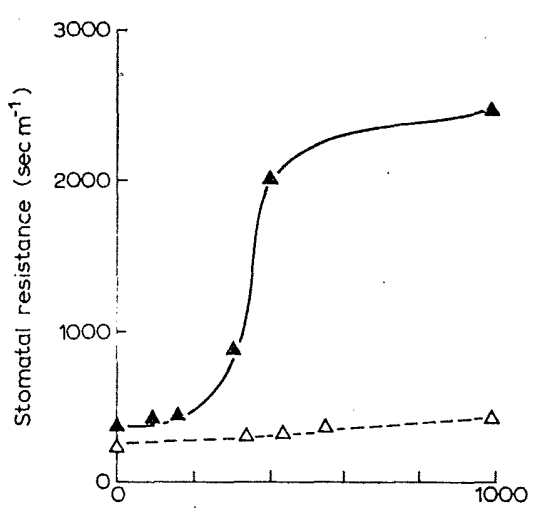

External $\mathrm{CO}_{2}$ concentration (ppm)

Fig. 7. Stomatal resistance in relation to external $\mathrm{CO}_{2}$ concentration: A. at $500 \mathrm{~J} \mathrm{~s}^{-1} \mathrm{~m}^{-2}$ in light intensity and $20^{\circ} \mathrm{C}$ air temperature; B. turnip data after Gaastra (1959) at two light intensities $\left(20.7 \cdot 10^{4} \mathrm{erg} \mathrm{s}^{-1} \mathrm{~cm}^{-2}\right.$ for dotted and 1.65 for solid) and air temperature $20.1^{\circ} \mathrm{C}$.

also grateful for financial support from the Japanese Ministry of Education and the Dutch Ministry of Education and Science for his stay in The Netherlands.

\section{REFERENCES}

De Wit, C. T., Brouwer R. and Penning de Vries, F. W. T., 1970. The simulation of photosynthetic systems. In: Prediction and Measurement of Photosynthetic Productivity. PUDOC, Wageningen, pp. 47-70.

Gaastra, P., 1959. Photosynthesis of crop plants as influenced by light, carbon dioxide, temperature, and stomatal diffusion resistance. Meded. Landb. Hogesch., Wageningen, 59: $1-68$.

Goudriaan, J., 1973. Crop simulation and experimental evaluation. SCSC Proc., 2: $827-829$.

Heath, O. V. S. and Russell, J., 1954. Studies in stomatal behaviour, VI. An investigation of the light responses of wheat stomata with the attempted elimination of control by the mesophyll. Part 2. Interactions with external carbon dioxide and general discussions. J. Exp. Bot., 5: 269-292.

Hsiao, T. C., Allaway, W. G. and Evans, L. T., 1973. Action spectra for guard cell Rb ${ }^{+}$ uptake and stomatal opening in Vicia faba. Plant Physiol., 51: 82-88.

Jones, R. J. and Mansfield, T. A., 1970. Increases in the diffusion resistances of leaves in a carbon dioxide-enriched atmosphere. J. Exp. Bot., 21: 951-958.

Mansfield, T. A. and Heath, O. V. S., 1963. Studies in stomatal behaviour, IX. Photoperiodic effects on rhythmic phenomena in Xanthium pennsylvanicum. J. Exp. Bot., 14: $334-352$.

Meidner, H. and Mansfield, T. A., 1968. Physiology of Stomata. McGraw-Hill, London, $179 \mathrm{pp}$. 
Pallas, J. E., 1965. Transpiration and stomatal opening with changes in carbon-dioxide content of the air. Science, 147: 171-173.

Pearson,.C. J., 1973. Daily changes in stomatal aperture and in carbohydrates and melate within epidermis and mesophyll of leaves of Commelina cyenea and Vicia faba. Aust. J. Biol. Sci., 26: 1035-1044.

Penning de Vries, F. W. T., 1972. A model for simulating transpiration of leaves with special attention to stomatal functioning. J. Appl. Ecol., 9: 57-77.

Stalfelt, M. G., 1962. The effect of temperature on the stomatal cells. Physiol. Plant., 15: $772-779$. 